\title{
Dual feedback in interpreter-mediated interactions: on the role of gaze in the production of listener responses
}

This article examines the coordination of listener responses and gaze in the production of dual feedback in triadic interpretermediated interaction. The focus is on backchannel responses in turn-medial position accompanied by a gaze shift from the interpreter to the 'principal', through which the recipient displays a change in the epistemic stance and/or affiliation. The analyses draw on a data set of interpreter-mediated interactions (Dutch-Russian) that were recorded with mobile eye-tracking glasses. The study shows that, through the production of dual feedback, recipients in a triadic, interpreter-mediated talk display momentary orientation to the participation status and knowledge states of their interlocutors. It is also argued that dual feedback objectifies the double conversational ground between the primary interlocutors and the interpreter, and plays an important role in maintaining a triadic participation framework in an interpreter-mediated dialogue. The study relates dual feedback to the existing models of interpreting and discusses the significance of the analysis for the current understanding of multimodality in interpreter-mediated interaction.

Keywords: Listener responses; Multimodality; Face-to-face interpreting; Eye-gaze in interaction; Participation framework

\section{Introduction}

In face-to-face communication, listeners are more than just passive recipients of speaker's talk. During extended units of talk, recipients actively signal their attention, understanding, (dis)agreement, assessment and affiliation through the use of verbal and visual listener responses or so-called backchannel responses (Bavelas \& Gerwing, 2011; Clark \& Brennan, 1991; Gardner, 2001; Norrick, 2010; Tolins \& Fox Tree, 2014; Yngve, 1970). These backchannel responses include verbal tokens (e.g. $\mathrm{mh}$ hm, yeah, okay, right, that's great) and visual practices, such as facial expressions, head nods and gestures (Gardner, 2001; Stivers 2008, Fox Tree \& Tolins, 2014). Through backchannel responses the recipient displays how (s)he understands the ongoing talk, which is essential for the emergence of intersubjectivity or common ground (Clark \& Brennan, 1991) in ongoing communication.

In this paper, we focus on backchanneling behavior in triadic, bilingual interactions with a consecutive interpreter. In comparison to the substantial body of literature on backchannel responses in same-language interaction, backchannel responses have received only little attention in research on interpreter-mediated interactions. According to Davidson (2002: 1277), "acknowledgment or acceptance turns are not easily found or identified" in interactions where the interlocutors do not understand each other's language and have to communicate with the aid of an interpreter. In particular mutual feedback between the primary participants is delayed or even non-existent in interpreter-mediated talk (Linell, Wadensjö \& Jönsson, 1992; Wadensjö, 1998). According to the collaborative model of conversational interpreting (Davidson, 2002), interpreter-mediated talk consists of two overlapping dyads, where two separate sets of common ground are co-constructed: between the interpreter and each of the primary participants, leaving no space for direct grounding between the participants. This implies that, during a dyadic exchange in one particular language, the participant who has no understanding of the language is temporarily 'excluded' from the conversation. However, previous studies on listener responses in interpreter-mediated encounters (Davidson, 2002; Linell, Wadensjö \& Jönsson, 1992; Wadensjö, 1998) have mainly been based on audio recordings and their transcriptions. Only a few studies have taken a multimodal approach, that takes into account the visual modality, to study listener responses in interpreter-mediated interaction (see Englund Dimitrova, 1997; Merlino \& Mondada, 2014; Vranjes et al. 2018). This paper aims at making a contribution in this direction by focusing on participants' nonverbal behavior and - in particular - gaze in the production of listener responses. 
Our paper examines a recurrent pattern of recipient behavior in turn-medial position, which we refer to as dual feedback. More specifically, we found that the recipient regularly shifts his/her gaze towards the other interlocutor while listening to the interpreter's rendition and that these gaze shifts in the majority of cases co-occur with a backchannel response. The phenomenon of interest can be illustrated by the following example of an interpretermediated encounter between a Russian-speaking exchange student and a Dutch-speaking university counsellor. In this extract, the interpreter (INT) is rendering the student's preceding turn into Dutch for the counsellor (CNS). Note that the green dots indicate the gaze direction of the counsellor, who is the recipient of the utterance.

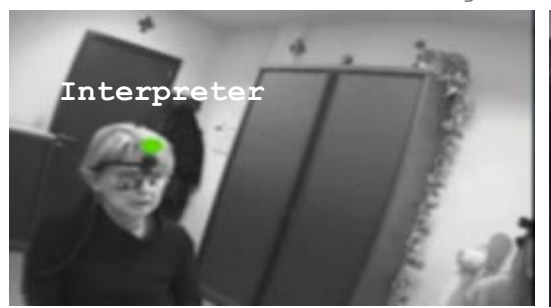

figure 1

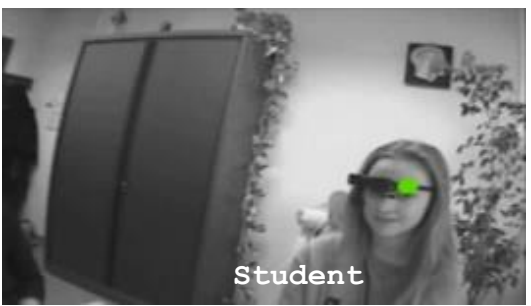

figure 2

4

\# (0.6)

fig $\quad \#$ fig 3

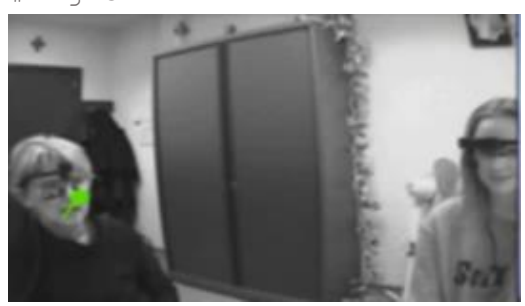

figure 3

5 INT euh vroeger hadden wij alle examens voor eenendertig december.

uh we used to have all the exams before the thirty-first of December

While listening to the interpreter's rendition of the student's talk, the counsellor produces a backchannel response 'ah ja' (line 3) in combination with a gaze shift towards the student. The counsellor orients towards the 'principal' (Goffman, 1981), whose utterance is being rendered in Dutch by the interpreter. The present analysis thus takes into account "the simultaneous use of semiotic resources by participants" (Goodwin, 2002: 1490) in the interaction.

Drawing on insights from Conversation Analysis and from research on multimodality in interaction, the aim of this study is to investigate such turn-medial backchannel responses that are produced in close correlation with gaze, as such forming a "composite signal" (Clark 1996): can we find some regularities in the production of this pattern? Which consequences does it have for the participation framework? The analysis is based on a dataset of nine interpreter-mediated interactions that were recorded with mobile eye-tracking glasses, which allow for a highly detailed analysis of gaze in ongoing communication (see also Brône \& Oben, 2015; Holler \& Kendrick, 2015). In this article, we present some preliminary findings on the work accomplished by dual feedback in interpretermediated interaction. After presenting a quantitative analysis on the relationship between gaze shifts and 
backchannel responses in turn-medial position (section 5), we focus on the sequential positioning of dual feedback in ongoing interpreted talk. Empirical data show that dual feedback can be seen as a recipient's heightened display of understanding and affiliation towards the 'principal' (Goffman, 1981) of the talk. Also, it is argued that dual feedback objectifies the double conversational ground between the primary interlocutors and the interpreter, and plays an important role in maintaining a triadic participation framework in an interpreter-mediated talk (section 7). Thus, this phenomenon throws light on new ways how temporarily "excluded" participants in this type of interaction are actually involved, even when they do not understand the language ${ }^{1}$. Finally, the study relates dual feedback to Davidson's (2002) collaborative model of interpreting and discusses the significance of the analysis for current understanding of multimodality in interpreter-mediated interaction.

\section{Backchannel responses and gaze direction in same-language interaction}

Backchannel responses are considered to be central for the success of communication as a joint activity (Clark \& Brennan, 1991; Gardner, 2001; Tolins \& Fox Tree, 2014). They comprise tokens with various interactional functions, including 'continuers' (Schegloff, 1982) such as $\mathrm{mm} \mathrm{hm}$ and uh huh, acknowledgments such as yeah (Drummond \& Hopper, 1993), newsmarkers and newsmarker-like tokens such as Really?, I see and Oh! (see, for example, Heritage, 1984) and assessments such as how nice, great (Goodwin, 1986) (for an overview of the different types of listener responses, see Gardner, 2001). They are not limited to verbal practices, but also include kinesic actions such as head nods, head shakes, facial expressions etc. (Goodwin, 1980; Stivers, 2008). Through the use of backchannel responses, the recipients display to the coparticipants "how they are analyzing and participating in the talk of the moment" (Goodwin, 1986) without taking a turn-at-talk-

Backchannel responses and continued attention are the most basic forms of positive evidence of understanding and are inherent in the collaborative process of grounding (Clark \& Schaefer, 1989; Clark \& Brennan, 1991) or the establishment of intersubjectivity in communication (Deppermann, 2015). Grounding is the process through which participants collaborate with each other moment by moment to establish the mutual belief that what has been said has been understood, or that it has been made part of their common ground "to a criterion sufficient for current purposes" (Clark \& Schaefer, 1989; Clark \& Brennan, 1991). This is accomplished through a three-step procedure: when an action-to-be-understood is presented by the speaker (i), the recipient should display how (s)he understands it (ii), and finally the speaker should display if (s)he accepts ${ }^{2}$ what (s)he takes up as the recipient's understanding of his/her turn (iii) (Deppermann, 2015: 66). This basic process, which is essential for conversational cooperation, is "an emergent, observable, shared product of the interaction" (Deppermann, 2015: 65-66). Grounding does not only proceed on a turn-by-turn basis, but also within unfolding phrases (see Goodwin, 1986; Goodwin \& Goodwin, 1987; Clark, 1996). This is where backchannel responses perform a crucial role. Being closely linked to the immediate context in which they are produced, backchannel responses reveal much about the recipient's stance towards the talk in progress and the development of intersubjectivity in interaction. For example, a change-of-state token such as 'Oh' marks that its producer has undergone some sort of change in his "current state of knowledge, information, orientation or awareness" (Heritage, 1984: 299). Even seemingly simple tokens such as 'mh hm' and 'yeah' are used by the recipient when there is opportunity to initiate repair, and thus indicate no problems of understanding with the turn so far (Clark \& Brennan, 1991; Gardner, 2001). Backchannel responses are thus an efficient way to establish common ground in interaction.

\footnotetext{
1 We want to thank the anonymous reviewer for this comment.

2 The third step, the acceptance phase, can be realized by the speaker's relevant next turn (Davidson, 2002).
} 
In dyadic interactions, the recipient's production of listener responses is strongly related to the behavior of the current speaker. As shown by previous research (Kendon, 1967; Goodwin, 1981; Bavelas et al., 2002; Stivers \& Rossano, 2010; De Kok \& Heylen, 2012) eye-gaze in particular has an important role in seeking and providing backchannel responses in dyadic face-to-face interactions. However, within a multiperson ${ }^{3}$ participation framework, the display of recipiency and collaboration is a more complex matter. In triadic interactions, that are of special interest in this study, the speaker may be addressing only one of the participants, while the third remains a momentarily 'unaddressed participant'4 (Bolden, 2013; Goffman, 1981) or a 'side-participant' (Goffman, 1981). On the other hand, two participants can be involved in the production of a telling, acting as 'consociates' (see Lerner, 1992) or 'comembers of a party of tellers' (see Bolden, 2013) to a third person. Gaze direction is then of particular importance to disambiguate who is being addressed at a particular moment during the talk and who is being selected to speak next (Rossano et al., 2009).

Interlocutors use gaze not only to address speech or to select the next speaker, but also to acknowledge the state of affairs between participants (Lund, 2007). As famously shown by Goodwin (1981), speakers orient to listener's knowledge states during the production of their talk. For example, while moving his/her gaze from an unknowing to a knowing recipient, the speaker may display uncertainty about some aspect of the telling that (s)he may share with the knowing recipient and ask for verification (Goodwin, 1981:153). Knowledge states (or epistemics) have also been shown to play an important role in conversational turn-taking (Lerner, 2003) and in the organization of participation in repair (Bolden, 2013). In the context of other-initiated repair in multiperson interaction, Bolden (2013) found that participants address repair initiation to the "owner of the experience" (or the 'principal' in Goffman's (1981) terms) and not to the 'animator', who produced the utterance. The participant with the 'epistemics of experience' has primary epistemic rights and responsibility over the trouble source to provide repair. As Bolden puts it, "when somebody talks about experiences or life circumstances of a copresent participant, that participant retains privileged access to what is being said" (2013: 320). Thus, knowledge appears to be a "moral domain" with clear implications for the management of social relationships (Stivers et al., 2011).

In the present paper, we focus on a specific type of multiperson interaction, i.e. bilingual, triadic interactions in which one of the participants is a consecutive interpreter. It will be argued that the recipients in such triadic interpretermediated talk display their sensitivity to their co-participants' participation statuses while producing backchannel responses. We will also show how this affects the establishment of a triadic participation framework.

\section{Backchannel responses in interpreter-mediated interaction}

\subsection{Differences in the participation status and the issue of speakership}

linterpreter-mediated dialogues are coordinated through the collaboration between the primary participants, who do not understand each other's language, and an interpreter. The interpreter typically provides renditions of one speaker's talk in every second turn, in the language of the other participant. In this way, the primary speaker's and the interpreter's voice are merged into one in the interpreter's rendition. The interpreter's involvement has often been discussed in terms of Goffman's (1981) production format according to which (s)he acts as an 'animator' (who produces the utterance) and/or 'author' (who selects the words and sentiments that are being expressed) (see e.g.

\footnotetext{
3 The term 'multiperson' instead of 'multiparty' is used here, as participants in an interaction may act collectively as a single unit or a multiperson "collectivity" (see Bolden, 2013).

4 The distinction between "addressed" and "unaddressed" is mainly based on speaker's visual orientation.
} 
Wadensjö, 1998, Pöchhacker, 2012). This is particularly evident in the interpreter's use of the first person pronoun (“I-form") to render the prior speaker's turn, which is in line with most codes of conduct for interpreters (Bot 2005). Speaking as the 'principal' (i.e. who is committed to the expressed stance and beliefs), on the other hand, is usually reserved for the primary speakers. In terms of the socially distributed rights to knowledge or epistemics, when the interpreter is rendering the thoughts, life circumstances, experiences and feelings of a primary participant, the latter remains the 'owner' of those thoughts and circumstances based on his/her 'epistemics of experience' (Bolden 2013). Thus, the interpreter has a different status and responsibilities with respect to knowledge 5 than the primary participants, who retain epistemic primacy or authority over the content of what is being said.

However, as Wadensjö rightly points out, "[t]he individual's participation status is partly a question of her own choice, partly a matter of how co-present people relate to her and to others present" (1998:93). Previous research has shown that primary participants can display various orientations towards the interpreter, treating him/her as a mere 'animator' of the preceding utterance or as a real 'speaker' in the interaction (Bot 2005, Mason 2012). Interpretermediated interactions are thus a particularly interesting setting to study how recipients orient to differences in participation status in ongoing conversation. As observed by Wadensjö:

"the interpreter-mediated conversation offers unique opportunities for researchers to trace how participation status is marked and confirmed in and by interaction. Through detailed analysis it should be possible to uncover how interlocutors understand the interaction order as interaction proceeds, (...) and how participants perceive the distribution of responsibility for the substance and the progression of current talk" (1998:94).

\subsection{Two overlapping dialogues within a complex participation framework}

One of the main challenges in conversing with the aid of an interpreter is "based largely in the difficulty in establishing reciprocity of understanding between the primary interlocutors in the discourse" (Davidson 2002: 1274). As they have little or no knowledge of each other's language, primary participants usually have to wait for the interpreter's rendition of the preceding talk in order to understand and react to what the other participant has said. According to Davidson's (2002) collaborative model of interpreting, interpreter-mediated interaction takes shape of two overlapping dyads where two sets of common ground are being co-constructed; between the interpreter and each of the primary participants. This means that the primary participants are fully dependent on the interpreter, whose task is not only to create shared understanding, but also to establish contact and rapport between the primary participants (Linell, Wadensjö \& Jönsson, 1992) ${ }^{6}$.

In this article, we are interested in recipient's backchannel responses that are produced during the interpreter's rendition. Englund Dimitrova (1997) noted that it is difficult for the interpreters to reproduce such listener responses, because the link between the recipient's response token and the part of the utterance that it is responding to would be lost. Moreover, it would be unclear whether the response token was part of the rendition of the previous speaker's turn or if it was produced by the interpreter as a reaction to the preceding utterance ('interpreter as responder', see

\footnotetext{
5 The interpreter does have some epistemic authority (or 'epistemics of expertise', see Bolden 2013) arising from her knowledge of both languages in the interaction, which allows her to speak on the behalf of the primary speakers. ${ }^{6}$ As pointed out by the anonymous reviewer, the primary participants can sometimes understand their coparticipant's language, which can lead to direct grounding between them.
} 
Baraldi \& Gavioli 2007). Thus, according to Englund Dimitrova, listener responses "often occur only once in interpreted discourse, in the original version" (1997: 160)7.

However, those studies (with the exception of Englund Dimitrova, 1997) were limited to the study of verbal backchannel responses. As in any type of face-to-face communication, interpreter-mediated interaction is characterized by its visibility and simultaneity (Clark 1996), and requires collaboration on every level of communication. As Goffman (1981: 130) put it: "sight is crucial, both for the speaker and for the hearer". In recent years, an increasing number of studies argues that the coordination of multimodal resources such as speech, gaze and gestures is of particular importance in this kind of complex interaction (Bot, 2005; Davitti, 2013; Davitti \& Pasquandrea, 2017; Krystallidou, 2014; Mason, 2012; Merlino \& Mondada 2014; Pasquandrea, 2011, 2012, Vranjes et al., 2018) ${ }^{8}$. According to Pasquandrea, "interpreter-mediated communication can benefit from multimodal analysis inasmuch as, by its own nature, it is a multiparty interaction, involving a complex participation format that is likely to be managed multimodally, rather than merely verbally" (2011: 456). It has been shown that an interpretermediated talk is coordinated through the collective efforts of all participants and that participants' visual behavior and orientation towards each other is crucial for the moment-by-moment negotiation of the (dyadic/triadic) participation framework ${ }^{9}$ (see Davitti \& Pasquandrea, 2017; Pasquandrea, 2011). However, as Davitti \& Pasquandrea (2017) point out, in current studies on the multimodal nature of an interpreter-mediated talk, "the embodied dimension often seems to be regarded as ancillary to talk, rather than integrated with it" (Davitti \& Pasquandrea, 2017: 24).

The goal of the present study is to investigate backchannel responses and gaze as co-occurring and related phenomena in the production of dual feedback in a data set of interpreter-mediated interactions. In particular, we focus on the role of gaze in the production of backchannel responses during the interpreter's extended renditions. It will be shown how recipients in an interpreter-mediated talk orient to the 'principal' while producing a backchannel response and how this affects the establishment of a triadic participation framework.

\section{Method \& Data}

The analysis is based on recordings of 9 interpreter-mediated interactions between a Russian-speaking student, a Dutch-speaking student counsellor and a professional interpreter at the University of Leuven. In total, three counsellors, three students and three professional interpreters participated in this study. Both the students and the student counsellors had no or very limited understanding of each other's language. The students were contacted to come to consultations with the counsellor (whom they were meeting for the first time) regarding their study program, their stay in Belgium and other issues and questions they might have. The encounters predominantly followed a question-answer pattern of interaction that characterizes many institutional interactions (Drew \& Heritage, 1992). Each conversation was interpreted consecutively into both languages by one of the three qualified

\footnotetext{
7 Merlini \& Favaron (2005), however, found a different pattern in their analysis of interpreter-mediated speech therapy sessions. The interpreters in their study often conveyed feedback parts, which was in line with the interactional goals of the session.

${ }^{8}$ For a detailed and very recent overview on the role of multimodality in interpreter-mediated interaction, see Davitti \& Pasquandrea (2017)

9 The participation framework refers to "participants' mode of presence in the interaction (...) their spatial lineup and orientations (vis-à-vis each other), their availability as recipients in terms of auditory and visual perception" (Deppermann, 2012:3).
} 
and experienced interpreters. Both the students and the counsellors had no or limited experience with talking through an interpreter. Each session was around 20 minutes in length, which amounts to $\sim 180$ minutes of recorded sessions. The participants gave their written informed consent prior to the conversations, in which it was stated what the study was about and how the data were going to be used.

Table 1 An overview of the data set

\begin{tabular}{l|lll}
\hline Session & Student & Counsellor & Interpreter \\
\hline 1 & S1: female & C1: male & I1: female \\
2 & S1: female & C1: male & 12: female \\
3 & S1: female & C1: male & I3: female \\
4 & S2: male & C2: female & 13: female \\
5 & S2: male & C2: female & 11: female \\
6 & S2: male & C2: female & 12: female \\
7 & S3: female & C3: female & 12: female \\
8 & S3: female & C3: female & 13: female \\
9 & S3: female & C3: female & 11: female \\
\hline
\end{tabular}

The participants were sitting in a triangular formation around a table (Figure 1), with the interpreter in the middle between the two participants. Each participant was wearing a pair of eye-tracking glasses (Pupil Pro Binocular Glasses and Arrington Gig-E60), which record participants' eye movements during ongoing interaction (Gullberg \& Kita, 2009). Eye-tracking makes it possible to register detailed gaze information (such as rapid gaze shift) in ongoing interaction, while at the same time capturing other semiotic channels, such as gesture and posture. In addition, a scene camera (Sony HDR-FX1000E) recorded the profile view of the interaction. For a full description of the recording method, see Vranjes et al. (2018). This resulted into 4 video recordings that were synchronized in Adobe Premiere Pro CS4 into one single video (see also Brône \& Oben, 2015; Vranjes et al., 2018) that could be imported into ELAN, a software package for transcription and annotation of multimodal data (Wittenburg et al., 2006).
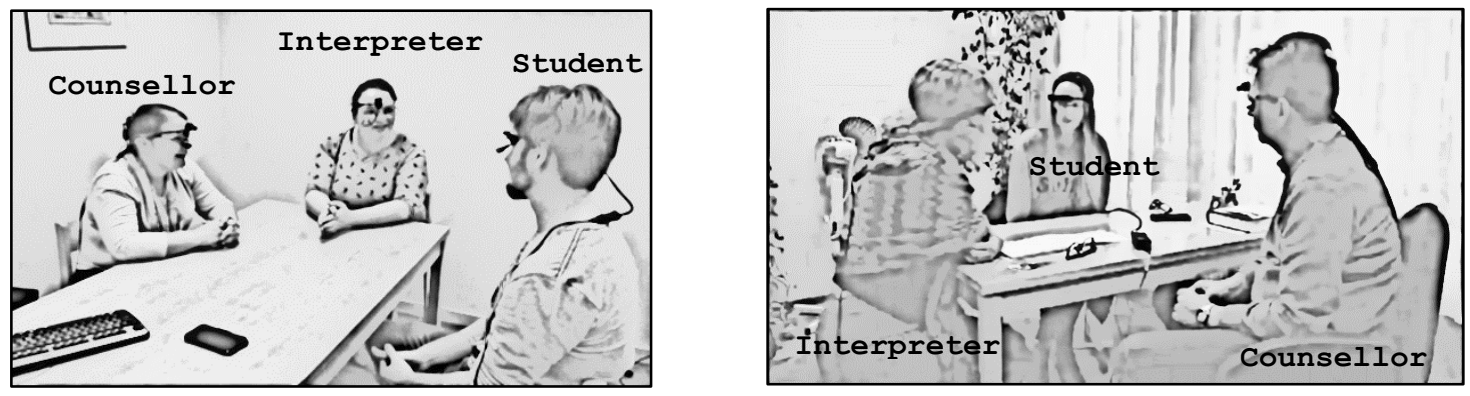

Figure 1: Profile shots of two interpreted interactions

The recordings were transcribed and coded for gaze direction and (non-)verbal backchannel responses in ELAN. In the present data set, we found that interpreters always gaze at the current speaker while producing backchannel responses. They are thus oriented at one interlocutor at the time while listening and memorizing what is being said. Primary participants (the counsellor and the student), on the other hand, display various patterns of feedback during the interpreter's renditions of the preceding turns. In the present study, the focus of the analyses will be on primary participants' backchannel responses during the interpreter's multi-unit turns. Therefore, we collected instances of primary participants' verbal and/or nonverbal backchannel responses in turn-medial position. (e.g. a head nod, verbal assessment, etc.) accompanied by a gaze shift. Such rapid gaze movements are often produced without a 
head reorientation towards the other participant and are thus difficult to capture with a video camera. Turn-final listener responses (see also Lerner, 1992) were not taken into account, where it is unclear whether listener's gaze shift is part of next-speaker selection (Rossano et al., 2009) or whether it is a cue for the producer's incipient speakership (Kendon, 1967) ${ }^{10}$.

We annotated listener responses in our data set in line with Gardner (2001), by making a distinction between continuers (e.g. $\mathrm{mm} \mathrm{hm}$ ), acknowledgments (e.g. ja), newsmarkers and other newsmarker-like objects (e.g. Oh, $A h$, Ah ja), assessments (e.g. leuk), collaborative completions, and nonverbal vocalizations and kinesic actions (e.g. laughter, head nods, head shakes). Very often, recipients produce verbal and nonverbal backchannel responses simultaneously. Following Bavelas et al. (2002:574), we treated "simultaneous or very closely sequential behaviors as a single listener response as long as their meaning was the same or complementary".

\section{Gaze and backchannel responses in turn-medial position}

In our data set, we found that counsellors regularly shift their gaze from the interpreter to the other interlocutor (or 'principal') while producing backchannel responses during the interpreter's renditions (see Figure 2). Our data set contained 168 instances of this pattern that we refer to as dual feedback. This section presents a quantitative analysis on the relationship between gaze and backchannel responses in the production of this pattern.

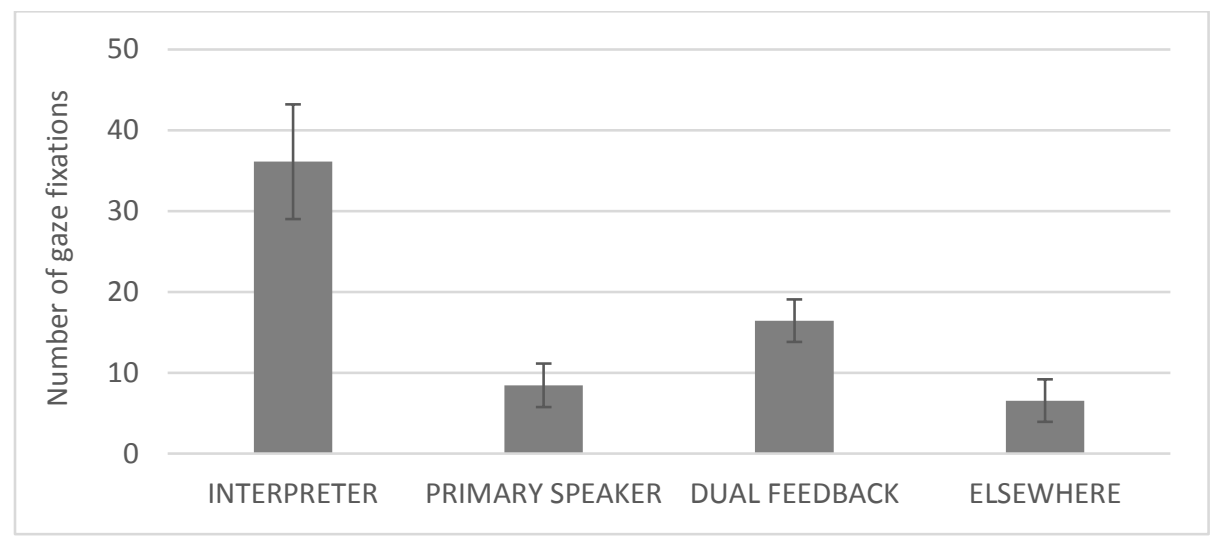

Figure 2. Relative distribution of counsellor's gaze direction during turn-medial feedback

A first step in the analysis of dual feedback pattern was to chart the relationship between counsellors' gaze and backchannel responses in turn-medial position during the interpreter's renditions. Interestingly, we found that $89 \%$ of all counsellor's gaze shifts in turn-medial position towards the student (or the 'principal') are coincident with a listener response. Thus, when the counsellor shifts his/her gaze towards the 'principal' during the interpreter's rendition, it is most likely to be coincident with some form of backchannel response, be it nonverbal or multimodal. The results indicate that those turn-medial gaze shifts coproduced with a backchannel response together form a "composite signal" (Bavelas et al., 2002; Clark, 1996) that contributes to the establishment of reciprocity between the primary participants. Furthermore, 95\% of listener responses that co-occur with a gaze shift are produced in combination with head nods ${ }^{11}$ (and, in a few cases, head shakes or head tilts). As such, dual feedback comprises a

\footnotetext{
10 However, in a few cases, it was clear that the listener did not anticipate the end of the current turn and in those instances turn-final listener responses were in fact a continuer or an acknowledgment token (see also Tolins \& Fox Tree 2014 concerning a posteriori categorizations).

${ }^{11}$ A head nod is considered to be a "rhythmical vertical head motion consisting of at least one down-up trajectory" (Stivers 2008: 37).
} 
strong multimodal signal. A possible explanation for this could be that dual feedback is meant to be seen (and potentially responded to) by the other primary participant. The visibility of the head nod in combination with a gaze shift makes it recognizable as one single action and is thus conducive to making the gaze shift noticeable to the other interlocutor. Also, head nods can be extended in time, which makes it easier to coordinate them with gaze shifts towards the other participant.

As shown in Table 2, newsmarkers and newsmarker-like objects such as Oh! and $A h$ ja, which mark the prior speaker's turn as in some sense newsworthy to the recipient (see Gardner, 2001), are mostly produced with a gaze shift towards the primary speaker. Thus, when displaying change in their state of knowledge, counsellors tend to orient towards the 'principal' (Goffman, 1981) or the party with the 'epistemics of experience' (Bolden, 2013) in the interpreter-mediated talk. This will be discussed further in section 7.

Table 2 Distribution of gaze shifts to the 'principal' in relation to the backchannel function

\begin{tabular}{c|c|c|c}
\hline Functional type & No gaze shift & Gaze shift to the principal & Total \\
\hline Newsmarker and newsmarker-like objects & $16(27 \%)$ & $\underline{43(73 \%)}$ & 59 \\
$($ e.g. Ah ja, Ah, Oh) & & $3(60 \%)$ & 5 \\
Assessments (e.g. leuk) & $2(40 \%)$ & $28(39 \%)$ & 72 \\
Acknowledgments $(e . g . j a)$ & $44(61 \%)$ & $27(41 \%)$ & 66 \\
Continuers (e.g. $\left.\mathrm{mh} \mathrm{hm}^{12}\right)$ & $39(59 \%)$ & & \\
\hline
\end{tabular}

Note that dual feedback was produced overwhelmingly by the counsellors during these encounters. This can be partly attributed to the differences in social roles between the counsellor and the student; the counsellor being the 'representative' of the faculty and the foreign student being a 'newcomer'. This is also reflected in their different orientations toward the interpreter: whereas the counsellors usually gaze at students while speaking, the students usually look at the interpreter. Also, in contrast to the students, the counsellors might have been driven by specific 'interpersonal goals' (Clark, 1996), namely to establish and maintain contact with the student during the talk. We will discuss this further in section 7, where we will argue that dual feedback is a manifestation of increased interpersonal engagement between primary participants.

In order to find out when dual feedback is produced and which consequences it has for the participation in interpreter-mediated talk, it is necessary to a closer look at the details of its production in its sequential context. After presenting the dominant gaze pattern during the production of backchannel responses in our data set (section 6), we will analyze the dual feedback pattern in more detail.

\section{Dominant gaze pattern: dyadic participation framework}

When the interpreter is speaking, the counsellors in most cases gaze at the interpreter while listening and producing backchannel responses to her rendition (Figure 2). We refer to this pattern as interpreter-directed feedback. An example of this pattern is shown in Extract 1. Prior to this excerpt, the counsellor had asked the student what he is

\footnotetext{
12 In our data set, recipients produced 'continuers' (see Schegloff, 1982) such as $\mathrm{mh} h m$ almost exclusively with head nods. Stivers (2008) argued that verbal continuers in turn-medial environment have a merely aligning, flooryielding function. Her study did not take into account the verbal continuers that are produced in combination with head nods.
} 
planning to do after he graduates. The following extract provides the interpreter's rendition of the student's answer. Note that all figures in the extract are screenshots from the eye-tracking cameras. The green dots in the figures represent the gaze direction from the perspective of the counsellor (figure 1 and 2 ) and from the perspective of the interpreter (figure 3).

\section{Extract 1}

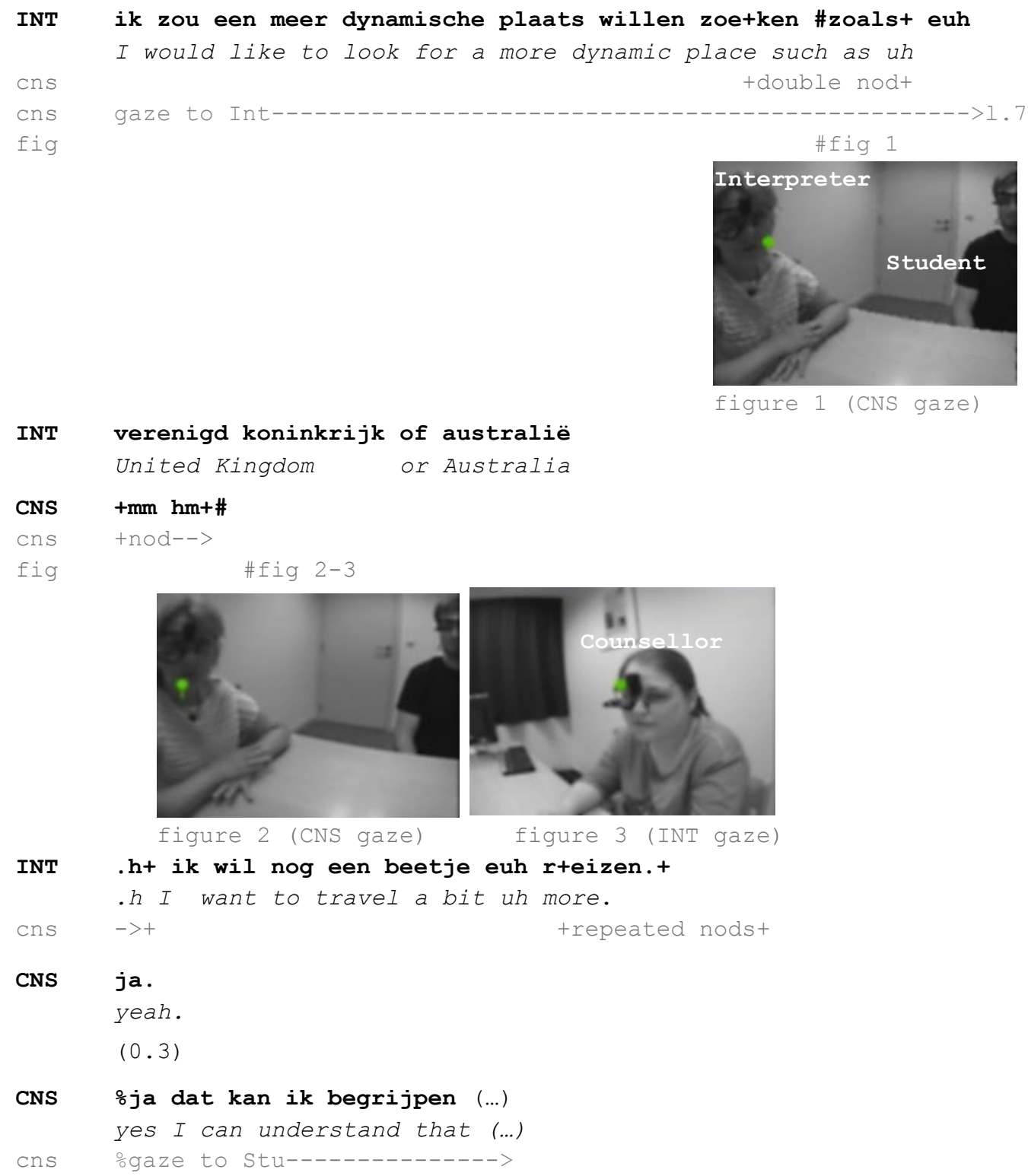

figure 1 (CNS gaze)

figure 2 (CNS gaze)

figure 3 (INT gaze) .ht ik wil nog een beetje euh rteizen.+ .h I want to travel a bit uh more.

The interpreter is rendering the student's talk into Dutch in the first person. Note that she is oriented towards the counsellor while rendering the student's preceding turn. As soon as the interpreter has finished formulating the turnconstructional unit 'I would like to look for a more dynamic place', the counsellor produces a nod to indicate her understanding of the prior utterance, while gazing at the interpreter (figure 1). Then, at the end of the turnconstructional unit in line 3, the counsellor produces a vocal continuer ('mm hm'), accompanied by a double nod, while keeping her gaze focused on the interpreter. By orienting to the interpreter in such a way, the counsellor foregrounds the interpreter's speakership. At the same time, the student - who has no understanding of Dutch - is left outside of the participation framework created by the counsellor's and interpreter's mutual orientation; he is 
momentarily excluded and relegated to the status of 'side participant' (Goffman, 1981). Only at line 7, when the counsellor takes the turn, does she orient her gaze at him. This excerpt fits nicely into Davidson's (2002) model of interpreted discourse, according to which interpreter'-mediated interaction consists of two separate (monolingual) dialogues, between the interpreter and each of the primary participants. This means that only one dyad is 'active' at a time. However, as we will show, the picture is not always that simple. This will be discussed in more detail in section 7 .

\section{Dual feedback and triadic participation framework}

The dual feedback pattern in the dataset is organized as follows:

(1) The counsellor is listening to the interpreter's rendition of the student's preceding turn.

(2) The counsellor shifts his/her gaze from the current speaker (interpreter) towards the student while producing a backchannel response. The student may align by producing a head nod towards the counsellor.

(3) The counsellor returns his/her gaze towards the interpreter who is still speaking, in line with Goodwin's (1980) rule that "a recipient should be gazing at the speaker when the speaker is gazing at the hearer". Alternatively, (s)he may maintain his gaze at the other student for a while (see section 7.2. for an example).

In the following, we discuss two environments preceding dual feedback in our data set: receipt of newsworthy information in the context of a (question-elicited) informing or counterinforming (section 7.1) and display of affiliation with the principal's stance in the context of an assessment (section 7.2).

\subsection{Receipting newsworthy information}

In our data set, dual feedback is frequently produced to register a change in the counsellor's state of knowledge towards the student (or 'principal'). This is usually the case in the context of (elicited) informings, that are typically constructed to deliver some information for a non-knowing recipient. We illustrate this in Extract 2. Prior to what is presented in this extract, the counsellor has asked whether secondary schools in Russia offer their students any help with the choice of a study domain for higher education, for example by helping them gather information or the like.

\section{Extract 2}

1 INT dus het olaatste ja+ar van 't school is het *tiende j*aa+r\#,

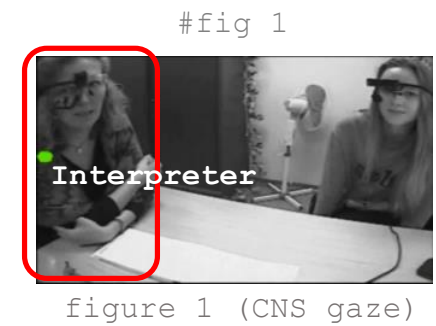


fig

\#fig 2

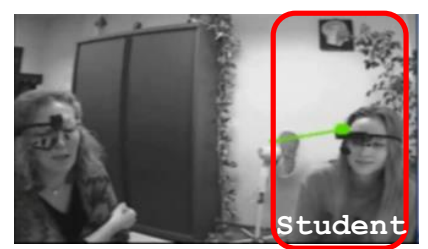

figure 2

\#ఃeuh+ w\#orden er verschillende cursussen georganistee\%rd\#,

uh

various courses are

organized

cns

cns

$->----+$

+surprised face->

fig

\#fig 3 \#fig 4
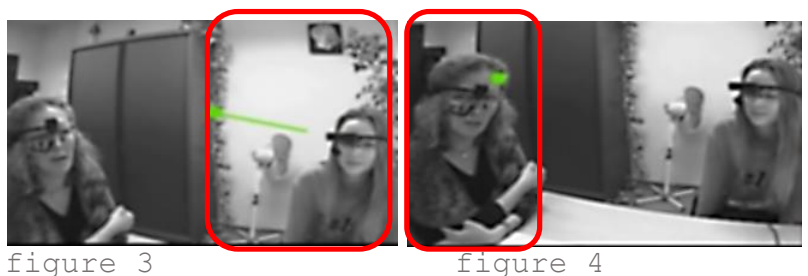

\#fig 5

$(0.3) \div$

cns

chs

INT

cn

cns

stu

CNS

INT

$9 \rightarrow$ CNS

cns

cns

stu

fig

+.h euh \#*waar euh* +de capaciteiten van de l+eerlingen worden getest, + uh where uhm the capacities of the pupils are tested

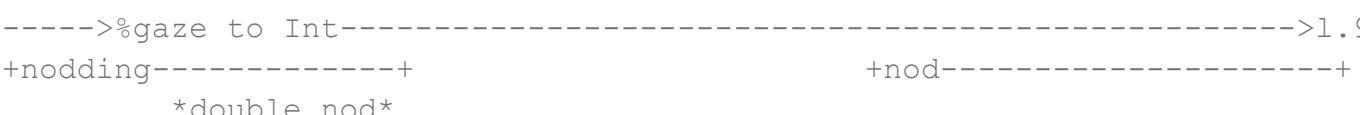

\#fig 6

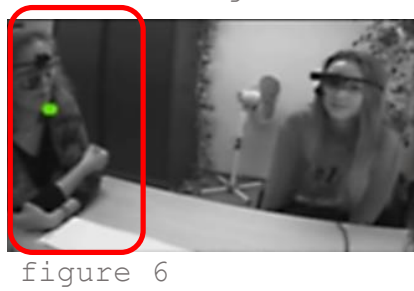

$\mathrm{mm}[\mathrm{hm}$,

[en op tbasis daarvant wordt een atanbeveling+ +ge+daa [\#०n

and on the basis of which a recommendation is made

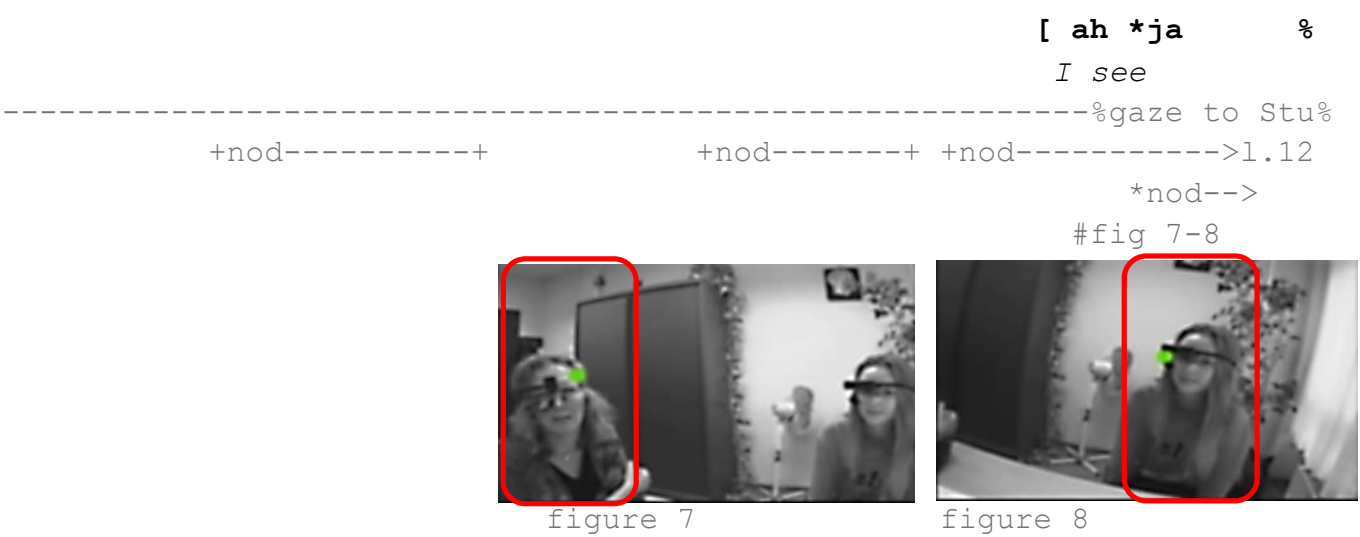

$(0.3) \div \#$ * 


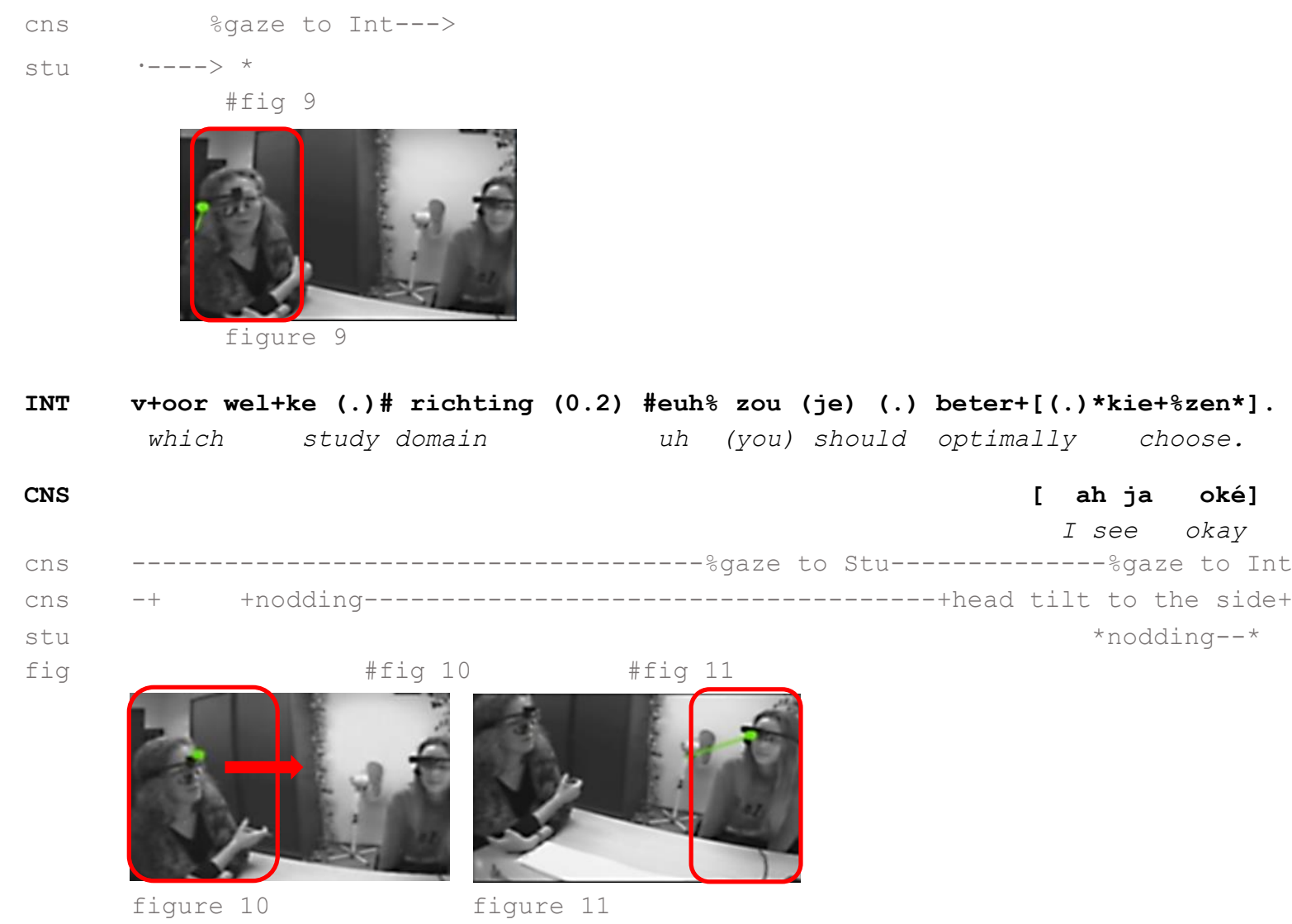

CNS ja. $(0.2)$ en is ook jouw keuze bepaald.

yes. and has your choice also been determined.

Instead of starting with a type-fitted response (a confirmation or a negation) to the counsellor's question, the interpreter begins with an informing action ('so the last year of school is the tenth year') in line 1, that introduces a contrast with the situation in Belgium (where the last year of secondary school is usually the sixth year). The counsellor starts producing an expansive nod with an upward movement of the head, that "foreshadows" his receipt of this informing as news (Whitehead 2011). At the end of the turn-constructional unit (TCU), he displays uptake by producing another head nod and shifting his gaze to the student (figure 2) during a 0.3-second pause (line 2). Thus, the gaze shift and the onset of the second nod are nicely timed to the point at which the interpreter's TCU reaches its possible completion. Interestingly, the student aligns by producing a head nod towards the counsellor. She does not look at the interpreter, who is rendering her preceding turn into Dutch, but maintains her head and gaze at the counsellor for the most part of the interpreter's rendition. As argued by Merlino \& Mondada (2014), by gazing at the counsellor during the interpreter's turn, the student displays herself as the 'principal' of the current talk. The counsellor immediately shifts his gaze back to the interpreter (figure 3) who is about to initiate the following TCU, thereby displaying his continuing attention and showing that he has no intention to take the turn.

The interpreter continues with the informing and at the end of the following TCU 'uh various courses are organized' (line 3), the counsellor again shifts his gaze towards the student (figure 5) while displaying surprise to the information provided with his facial expression. This action marks his receipt of the content of the TCU as newsworthy in some way and is then followed by a series of nods. The interpreter appears to follow the counsellor's gaze movement as she shifts her gaze to the student as well. Again, the student acknowledges the counsellor's display of surprise by producing a head nod towards him, although she does not understand Dutch. The counsellor then moves his gaze back to the interpreter (figure 6), who continues with the specification of the content of those courses. During the 
interpreter's utterance, the counsellor starts nodding and at the end of the TCU (line 5), he produces a continuer ('mm hm'). Unlike in previous cases, the counsellor maintains his gaze at the interpreter, as he is merely indicating to her that the utterance has been received and that she may continue (Tolins \& Fox Tree, 2014). Also, the student does not display alignment here with a head nod.

Following the information that 'a recommendation' (line 8) is made on the basis of those tests, the counsellor starts producing a nod with an upward head movement followed by the newsmarker 'ah ja' (/ see), while shifting his gaze towards the student (figures 7-8). The counsellor thus addresses successively both interlocutors with his gaze while producing the listener response. Through this composite signal, he displays a change in his knowledge state and at the same time acknowledges the other interlocutor's epistemic authority (Bolden, 2013; Heritage, 2012) over the content of the talk. Again, the student aligns with this expression of change in counsellor's knowledge state by responding with a head nod towards the counsellor. There appears to be some form of preliminary (or semi)grounding at that stage: although the student cannot check on what the interpreter says at the moment, she acknowledges the counsellor's change in information state ${ }^{13}$.

In line 11, then, the interpreter continues with further specification 'which study domain uh (you) should optimally choose'. As she utters 'study domain' (richting), she starts moving her head and gaze towards the student (figure 10), while lifting her hand and gesturing in student's direction. The counsellor immediately follows by directing his gaze at the student (figure 11) and maintaining it at her. In contrast to the previous cases, this gaze shift was brought about by the interpreter's gaze and head movement towards the student (for 'gaze cueing', see Frischen et al., 2007). Also, the gaze shift occurs towards the end of the interpreter's turn, which is marked by slowing down of the pace of the interpreter's rendition. As it is unclear how this gaze shift is motivated, we did not count it as an instance of dual feedback in our analysis. At the end of the interpreter's turn, the counsellor produces 'ah ja' followed by 'oké' (okay), which is used to pre-figure changes in topic or activity (Gardner 2001: 55).

Another example is provided in Extract 3. The counsellor had asked the student what type of program she is following as part of her exchange in Belgium (not presented in the transcript). Here, the interpreter starts her rendition with the counterinforming 'it is not an exchange' (line 1), that explicitly rejects the counsellor's presupposition. The counsellor immediately responds to this TCU with the newsmarker 'ah okay', that indicates a shift in her information state, while moving her gaze to the student. The student responds to this with head nods toward the counsellor while maintaining her gaze at her.

\section{Extract 3}

1 INT . . h het is niet uitowisseling,\#

.h it is not an exchange

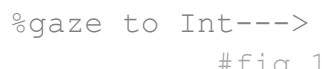

\footnotetext{
${ }^{13}$ As commented by the anonymous reviewer, "it is true that the student cannot check, but she probably takes it for granted that the interpreter is saying how she was told. There is a problem of trust, which, although being basically ignored in interpreting traditional literature, seems to be very much at stake here".
} 


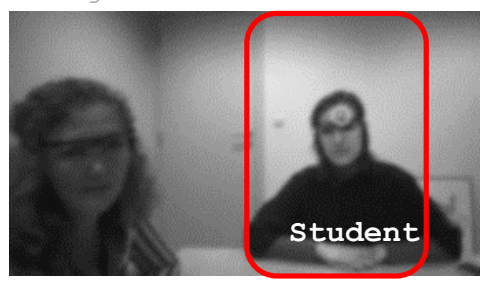

We have shown that during the interpreter's ongoing turn, the counsellor displays his just-changed state of knowledge to the 'principal' and not to the interpreter. Gaze is in those instances "wholly interactive and a function of a communicative intent" (Lund, 2007:299). By displaying a change in the epistemic state directly to the student, the counsellor reduces the epistemic asymmetry (Bolden, 2013) between himself and the student already before he can take a turn-at-talk. The student aligns with this change in epistemic position by producing a head nod towards the counsellor. With dual feedback, the counsellor also acknowledges the epistemic authority of the student over what is being said (as the 'principal'); although the interpreter has knowledge of the other language and of the content of the student's talk, she and the student have different states of knowledge in relation to what is being expressed.

\subsection{Displaying agreement or affiliation with the participant whose stance is being expressed}

The following example shows how dual feedback can perform a 'social-affiliational' function during the interaction. We have found that counsellors produce dual feedback in the environments where student's stance toward a situation is expressed (as being funny, sad, awful or exciting). Stance taking is another social activity in which intersubjective understanding between interlocutors is publicly displayed. The most typical and recognizable environment of stance taking are assessments, which typically make relevant an affiliative uptake on the part of the responder that mirrors the speaker's conveyed stance (see Stivers 2008). An example is provided in Extract 3. Prior to the excerpt, the student was telling that he will be abroad during the summer. After the counsellor assessed this information in a positive way, the student recounts that it is actually not the best timing to go abroad. In the following excerpt, we provide the interpreter's rendition of the student's turn.

\section{Extract 4}

1 INT

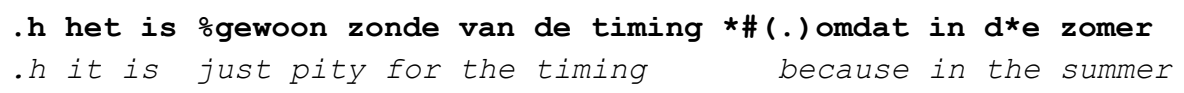




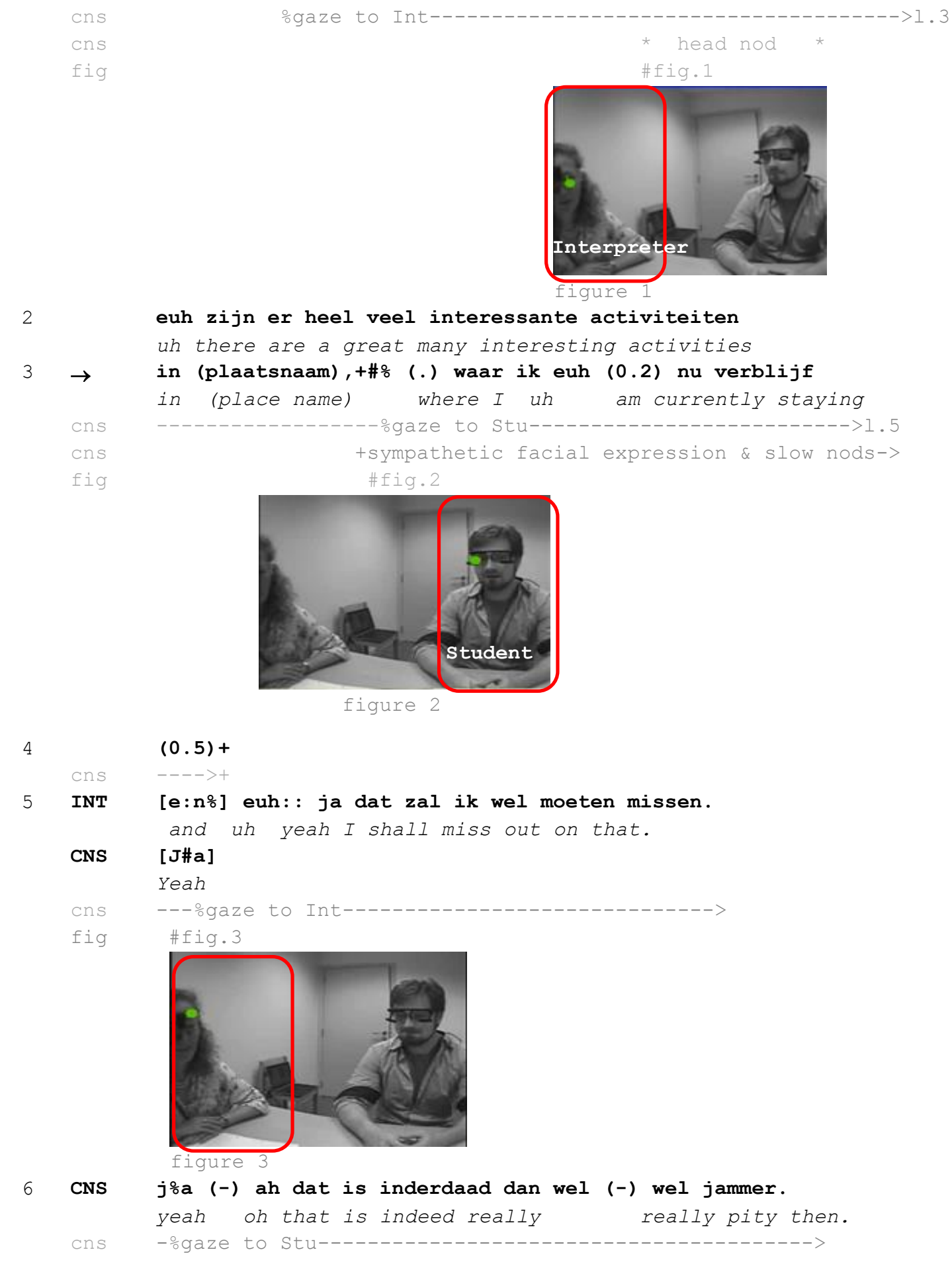

At the end of the TCU 'pity about the timing' (line 1), the counsellor produces a single head nod, while maintaining her gaze at the interpreter (figure 1). Note that at that point, the counsellor does not yet have full access to the reason as to why it could be a bad timing for the student to go abroad. Only after the interpreter has provided the reason for it in lines 1-2 ('because in the summer there are great many interesting activities') does the counsellor gain full understanding of the student's stance. She immediately displays her increased understanding and affiliation (see also Stivers, 2008) with the expressed stance by shifting her gaze towards the student (figure 2), who is looking 
at her, and making a sympathetic facial expression accompanied by a series of slow, repeated nods ${ }^{14}$. Thus, the counsellor's affiliative backchannel response is directed to the 'principal', whose views are being expressed and who retains primary epistemic rights over what is being said, and not merely to the interpreter who produces the utterance. The counsellor and the student stay engaged in mutual gaze for 2 seconds. As noted by Kendon "extended mutual gazes appear to be indicative of an intensifying of the direct relations between the participants" (1967:48). In other words, there is a moment of convergence in stance (see also Haddington, 2009) between the primary participants during the interpreter's rendition. This is important for strengthening of the interpersonal relationship between primary participants and for the establishment of a triadic participation framework. After the student withdraws his gaze, the counsellor turns her attention to the interpreter (figure 3 ). At the end of the interpreter's turn, the counsellor verbalizes her understanding and affiliation with 'that is indeed really pity' (line 6). This example thus shows how "[t]he informational and social-affiliational functions of common ground are closely interlinked" (Enfield, 2008: 229) in social interactions.

\section{Conclusion}

This study makes a contribution to the almost non-existing multimodal accounts of backchannel responses in interpreter-mediated interactions and, more broadly, to multimodality research that takes into account participants' simultaneous employment of various semiotic resources (Goodwin, 2002). Through the examination of the dual feedback pattern in our data set, we demonstrated the crucial role of recipient's gaze direction in the production of backchannel responses and in the establishment of a triadic participation framework in interpreter-mediated interactions.

Extending Davidson's (2002) analysis that focused on the achievement of reciprocity at the verbal level in interpreter-mediated talk, the current study has shown how participants who have no access to each other's language can nevertheless achieve reciprocity of understanding through gaze and listener responses. Dual feedback thus appears to further the accomplishment of common ground and reciprocity between the primary participants and, as such, objectifies the double conversational ground between the primary interlocutors and the interpreter. Also, it exemplifies the relevance of backchannel responses in interpreter-mediated talk not just for the achievement of common ground or intersubjectivity in interaction, but also on an interpersonal level. As argued by Enfield "our efforts to maintain and build common ground have significant consequences for the type of relationship we succeed in ongoingly maintaining, that is, whether we are socially close or distant" (Enfield, 2006: 230). Dual feedback appears to be an active communicative signal, produced at specific moments during the interpreter's rendition, through which the recipient tries to engage with the 'principal' of the current talk.

Furthermore, through dual feedback, recipients in an interpreter-mediated encounter display their orientation to the participation status and speaking rights of their interlocutors. While producing dual feedback, the recipient addresses both participants, who are momentarily acting as 'consociates' (Bolden, 2013) and who both have the epistemic access to the content of the talk, but not the same epistemic authority over what is being said. Although the 'principal' relies on the interpreter to express her experience or thoughts in the other language, (s)he nevertheless retains the epistemic authority as 'experiencer' of those thoughts and experiences. The analysis has shown that dual feedback occurs strikingly often with newsmarkers (Gardner 2001), pointing to the fact that the recipient wants to indicate directly to the 'principal' that the information is newsworthy in some way and that a

\footnotetext{
14 It has been shown that the more affliative, supportive tokens "are more varied in intonation, in lexical selection and also in length" (Müller, 1996, in Gardner, 2001: 20).
} 
change in the knowledge state has occurred. Furthermore, we have demonstrated how recipient displays affiliation with the 'principal', whose stance is being expressed, rather than with the interpreter, who is merely producing it in the recipient's language. As Wadensjö (1998: 93) puts it: “To interact means to continuously evaluate others' and one's own relation to a focused discourse". So even when producing backchannel responses, the recipient orients to the "socially distributed rights to knowledge" (Bolden, 2013) in the ongoing interaction. Thus, dual feedback shows that participants in an interpreter-mediated talk are cognizant of their own and others' position in the triad and that this feeds into a continuous process of 'interaction management' in this type of interaction.

We have also seen that the recipient's redirection of gaze towards the 'principal' provides for a subtle shift in the participation framework during its production, which helps to maintain a triadic interaction pattern. As such, dual feedback appears to be a manifestation of increased social engagement between primary participants and it shows how the participation framework is constantly negotiated in this type of interaction. Thus, although they are dependent on the interpreter's renditions of the talk to achieve mutual understanding, the construction of reciprocity and the management of the interaction on the level of the triad is to a large extent in the hands of the primary participants.

Finally, the present study has illustrated the importance of a multimodal approach in gaining a better understanding of the intersubjective relations among the interlocutors in an interpreter-mediated talk. Moreover, a methodological approach that enables the detailed study of synchronous gaze behavior can help us gain insights into the specific multimodal character of an interpreter-mediated encounter, which can further contribute to our knowledge of the subtleness in the multimodal exchange. Future research will be needed to investigate the dual feedback pattern in other constellations in face-to-face (interpreted or same-language) interactions, which will undoubtedly broaden our understanding of the phenomenon.

\section{Appendix: Transcription conventions}

Speech is transcribed according to GAT2 (for details see Selting et al., 2009). Conventions for the multimodal transcription are adopted from Mondada (see

https://franzoesistik.philhist.unibas.ch/fileadmin/user_upload/franzoesistik/mondada_multimodal_conventions.pdf).

[ ] simultaneous speech

(.) micropause (shorter than 0.2 seconds)

(-) $\quad$ short pause (duration between 0.2 . and 0.5 seconds)

.h in-breath

(text) unclear or dubious words

$:,:, \cdots \quad$ lengthening or prolongation of a sound (sound stretch), according

to duration

$+\quad$ delimits gestures by the counsellor

$\% \quad$ delimits counsellor's gaze direction

* delimits gestures by the student

*---> the action described continues across subsequent lines

--->* until the same symbol is reached

\# $\quad$ symbol \# specifies the exact moment at which the image refers.

This is done by inserting the symbol both on the line of the talk and on the line dedicated to the image (fig. in the margins) 


\section{References}

Angelelli, Claudia, 2000. Interpretation as a Communicative Event : A Look through Hymes' Lenses. Translators' Journal 45 (4), 580-592.

Baraldi, Laura, Gavioli, Claudio, 2012. Understanding coordination in interpreter-mediated interaction. In: Baraldi, L., Gavioli, C. (Eds.), Coordinating Participation in Dialogue Interpreting. Benjamins Publishing, Amsterdam/Philadelphia, pp. 1-22.

Bavelas, Janet Beavin, Coates, Linda, Johnson, Trudy, 2002. Listener responses as a collaborative process: The role of gaze. Journal of Communication, 566-580.

Bavelas, Janet Beavin, Gerwing, Jennifer, 2011. The Listener as Addressee in Face-to-Face Dialogue. International Journal of Listening 25, 178-198.

Bolden, Galina B., 2013. Unpacking "Self": Repair and Epistemics in Conversation. Social Psychology Quarterly 76 (4), 314-342.

Bot, Hanneke, 2005. Dialogue Interpreting in Mental Health. Rodopi Publishers, Amsterdam and New York.

Brône, Geert, Bert, Oben, 2015. InSight Interaction. A multimodal and multifocal dialogue corpus, Language Resources and Evaluation 49, 195-214.

Clark, Herbert H., 1996. Using Language. Cambridge University Press, Cambridge.

Clark, Herbert, Brennan, Susan, 1991. Grounding in communication. In: Resnick, L. B., Levine J.M., Teasley, S.D. (Eds.), Perspectives on socially shared cognition. APA Books, Washington, pp. 127-149.

Clark, Herbert H., Schaefer, Edward F., 1989. Contributing to discourse. Cognitive Science 13, 259-294.

Davidson, Brad, 2012. A model for the construction of conversational common ground in interpreted discourse. Journal of Pragmatics 34, 1273-1300.

Davitti, Elena, 2013. Dialogue Interpreting as Intercultural Mediation: Interpreter's use of upgrading moves in parentteacher meetings, Interpreting 15 (2), 168-199.

Davitti, Elena, Pasquandrea, Sergio, 2017. Embodied participation: What multimodal analysis can tell us about interpreter-mediated encounters in pedagogical settings. Journal of Pragmatics 107, 105-128.

De Kok, Iwan, Heylen, Dirk, 2012. Analyzing nonverbal listener responses using parallel recordings of multiple listeners. Cognitive Processing 13, 499-506.

Deppermann, Arnulf, 2015. When recipient design fails: Egocentric turn-design of instructions in driving school lessons leasing to breakdowns of intersubjectivity. Gesprächsforschung - Online Zeitschrift zur verbalen Interaktion 16, 63-101.

Drew, Paul, Heritage, John, 1992. Talk at Work: Interaction in Institutional Settings. Cambridge University Press, Cambridge.

Drummond, Kent, Hopper, Robert, 1993. Back channels revisited. Acknowledgment tokens and speakership incipiency. Research on Language and Social Interaction 26, 157-178.

Englund Dimitrova, Birgitta, 1997. Degree of Interpreter Responsibility in the Interaction Process in Community Interpreting. In: Carr, S.E. (Ed.), The Critical Link: Interpreters in the Community. Benjamins, Amsterdam/Philadelphia, pp. 147-164.

Enfield, Nick J., 2008. Common ground as a resource for social affiliation. In: Kecskes, I., Mey, J. L. (Eds.), Intention, common ground and the egocentric speaker-hearer. Mouton de Gruyter, Berlin, pp. 223-254.

Gardner, Rod, 2001. When Listeners Talk: Response tokens and listener stance. Benjamins Publishing, Amsterdam.

Goffman, Erving, 1981. Forms of Talk. University of Pennsylvania Press, Philadelphia.

Goodwin, Charles, 1981. Conversational Organization. Interaction between Speakers and Hearers. London: Academic, New York. 
Goodwin, Charles, Goodwin, Marjorie Harness, 2004. Participation. In: Duranti, A. (Ed.), A Companion to Linguistic Anthropology. Basil Blackwell, Oxford, pp. 222-244.

Goodwin, Charles, 1986. Between and Within: Alternative Treatments of Continuers and Assessment. Human Studies 9 (2), 205-217.

Gravano, Agustin, Hirschberg, Julia, Beňuš, Štefan, 2013. Affirmative Cue Words in Task-Oriented Dialogue. Computational Linguistics 38 (1).

Gullberg, Marianne, Kita, Sotaro, 2009. Attention to speech-accompanying gestures: Eye movements and information uptake. Journal of Nonverbal Behaviour 33, 251-277.

Haddington, Pentti, 2006. The organization of gaze and assessments as resources for stance taking. Text \& Talk 26 (3), 281-328.

Heritage, John, 1984. A change-of-state token and aspects of its sequential placement. In: Atkinson, M., Heritage, J. (Eds.), Structures of Social Action: Studies in Conversation Analysis. Cambridge University Press, Cambridge, pp. 299-345.

Heritage, John, 2011. Territories of knowledge, territories of experience: Empathic moments in interaction. In: Stivers, T., Mondada, L., Steensig, J. (Eds.), The morality of knowledge in conversation. Cambridge University Press, Cambridge.

Holler, Judith, Kendrick, Koben H., 2015. Unaddressed participants' gaze in multi-person interaction: Optimizing recipiency. Frontiers in Psychology 6 (98), 1-14.

Enfield, Nick J., 2008. Common ground as a resource for social affiliation. In: Kecskes, I., Mey, J. L. (Eds.), Intention, common ground and the egocentric speaker-hearer. Mouton de Gruyter, Berlin, pp. 223-254.

Frischen, Alexandra, Bayliss, Andrew, Tipper, Steven P., 2007. Gaze cueing of attention: Visual attention, social cognition, and individual differences. Psychologial Bulletin 133, 694-724.

Kendon, Adam. 1967. Some functions of gaze-direction in social interaction. Acta Psychologica 26, 22-63.

Kendon, Adam, 2002. Some uses of the head shake. Gesture 2 (2), 147-182.

Kidwell, Mardi, 1997. Demonstrating Recipiency: Knowledge Displays as a Resource for the Unaddressed Participant. Issues in Applied Linguistics 8 (2), 85-96.

Krystallidou, Demi, 2014. Gaze and body orientation as an apparatus for patient inclusion into exclusion from a patient-centred framework of communication. The Interpreter and Translator Trainer 8 (3), 399-417.

Lerner, Gene H. 1992. Assisted Storytelling: Deploying Shared Knowledge as a Practical Matter. Qualitative Sociology 15 (3), 247-271.

Lerner, Gene H., 2003. Selecting next speaker: The context-sensitive operation of a context-free organization. Language in Society 32, 177-201.

Linell, Per, Wadensjö, Cecilia, Jönsson, Linda, 1992. Establishing Communicative Contact through a Dialogue Interpreter. In: Grindsted, A., Wagner, J. (Eds.), Communication for Specific Purposes - Fachsprachliche Kommunikation. Gunter Narr Verlag, Tübingen, pp. 125-142.

Lund, Kristine, 2007. The importance of gaze and gesture in interactive multimodal explanation. Language Resources and Evaluation 41, 289-303.

Mason, Ian, 2012. Gaze, positioning and identity in interpreter-mediated dialogues. In: Baraldi, L., Gavioli, C. (Eds.), Coordinating Participation in Dialogue Interpreting. Benjamins Publishing, Amsterdam/Philadelphia, pp. 177-199. Merlino, Sara, Lorenza, Mondada, 2014. Identités fluides dans le travail interactionnel du traducteur improvisé. In : Greco, L., Mondada, L., Renaud, P. (Eds.), Identités en interaction. Faits de Langue, pp. 87-144.

Mondada, Lorenza, 2013. Video as a tool in the social sciences. In: Müller, C., Cienki, A., Fricke, E., Ladewig, S. H., McNeill, D., Teßendorf, S. (Eds.), Body - Language - Communication: An International Handbook on Multimodality in Human Interaction, Vol. 1. De Gruyter Mouton, Berlin. pp. 982-992. 
Norrick, Neal R., 2010. Listening practices in television celebrity interviews. Journal of Pragmatics 42, 525-543.

Pasquandrea, Sergio, 2011. Managing multiple actions through multimodality: Doctors' involvement in interpretermediated interactions. Language in Society 40 (4), 455-481.

Pasquandrea, Sergio, 2012. Co-constructing dyadic sequences in healthcare interpreting: A multimodal account. New Voices in Translation Studies 8, 132-157.

Pöchhacker, Franz, 2012. Interpreting participation. Conceptual analysis and illustration of the interpreter's role in interaction. In: Baraldi, L., Gavioli, C. (Eds.), Coordinating Participation in Dialogue Interpreting. Benjamins Publishing, Amsterdam/Philadelphia, pp. 201-228.

Rossano, Federico, Brown, Penelope, Levinson, Stephen C., 2009. Gaze, questioning, and culture. In: Sidnell, J. (Ed.), Conversation analysis: Comparative perspectives. Cambridge University Press, pp. 187-249.

Schegloff, Emanuel A., 1982. Discourse as an interactional achievement: Some uses of 'uh huh' and other things that come between sentences. In: Tannen, D. (Ed.), Analyzing Discourse: Text and Talk. Georgetown University Roundtable on Languages and Linguistics 1981. Georgetown University Press, Washington, DC, 71-93.

Stivers, Tanya, 2008. Stance, alignment and affiliation during story telling: when nodding is a token of preliminary affiliation. Research on Language in Social Interaction 41, 29-55.

Stivers, Tanya, Rossano, Federico, 2010. Mobilizing Response. Research on Language and Social Interaction 43 (1), 3-31.

Stivers, Tanya, Mondada, Lorenza, Steensig, Jakob, 2011. Knowledge, morality and affiliation in social interaction. In: Stivers, T., Mondada, L., Steensig, J. (Eds.), The morality of knowledge in conversation. Cambridge University Press, Cambridge, pp. 3-26.

Tolins, Jackson, Fox Tree, Jean E., 2014. Addressee backchannels steer narrative development. Journal of Pragmatics 70, 152-164.

Vranjes, Jelena, Bot, Hanneke, Feyaerts, Kurt, Brône, Geert, 2018. Displaying recipiency in an interpreter-mediated dialogue: an eye-tracking study. In: Oben B., Brône, G. (Eds.), Eye-tracking in interaction. Studies on the role of eye gaze in dialogue. Amsterdam: Benjamins.

Wadensjö, Cecilia, 1998. Interpreting as interaction. Longman, London and New York.

Whitehead, Kevin A., 2011. Some uses of head nods in 'third position' in talk-in-interaction. Gesture 11(2), 103122.

Wittenburg, Peter, Brugman, Hennie, Russel, Albert, Klassmann, Alex, Sloetjes, Han, 2006. ELAN: a Professional Framework for Multimodality Research. In: Proceedings of LREC 2006, Fifth International Conference on Language Resources and Evaluation.

Yngve, Victor H., 1970. On getting a word in edgewise. In: Papers from the Sixth Regional Meeting of the Chicago Linguistic Society. Chicago Linguistic Society, Chicago, pp. 567-577. 